\title{
OBITUARY
}

\section{Joseph Raeburn Mutch}

THE death of Dr. J. R. Mutch on Coronation Day at the age of 58 has robbed the Aberdeen area of one of its best known and popular ophthalmologists.

Joseph Raeburn Mutch began life with no favour from fortune. He was one of a large $\stackrel{\mathbb{D}}{\circ}$ family in a household that knew not affluence, and for some years of his boyhood he was an invalid with hip-joint trouble to whom interested school teachers sent his daily lessons, $\vec{o}$ and who filled in his time with what occupational therapy was available.

When his general health improved, he was apprenticed to a watch-maker-a sheltered $\vec{\omega}$ occupation doubtless chosen on account of his health, but one well suited to his flair for $\frac{}{0}$. construction and creation, and an excellent training ground for his later vocation. During $\underset{\omega}{\omega}$ the first World War he was accepted for clerical duties with the Gordon Highlanders, and $D_{\infty}$ was later transferred to the instrument department of the R.A.F. The combination of $r$ sight-testing with watch-making opened for him a new world-but too limited a world $\vec{N}$ for his courage and sense of adventure. Not till he could himself operate on a patient $\stackrel{5}{3}$ and give back the blessing of sight would that passionate quest be satisfied. Accordingly, $\vec{P}$ though by this time in his middle thirties, married, and with an established business of his own in Aberdeen as a watch-maker, jeweller, and optician (which he kept on to within क्ञ 6 months of qualifying), he set about the study of medicine. He graduated M.B., Ch.B., $\vec{\bullet}$ at Aberdeen in 1934; the following year, after having filled a resident post in the Aberdeen $\mathrm{E}$ Royal Infirmary, he went to London and took his D.O.M.S., and in 1936 obtained his M.D. In 1937 Dr. Mutch joined the staff of the Aberdeen Royal Infirmary as an assistant surgeon, and soon built up a large private practice. After the National Health Act came $\bar{O}$ into force he took full-time duty under the Hospital Service-a choice he never regretted. \%

Dr. Mutch was a forthright man, without pretence. He still spoke unashamedly the $\stackrel{\mathbb{D}}{\square}$ broad accents of his native Banffshire. His work was good and he knew it, as did the $\overrightarrow{0}$ many patients to whom he brought relief and healing. His most outstanding characteristic was his courage and in the last few weeks he faced death unflinchingly. He was a man of simple joys-his unique collection of clocks and barometers, and above all his garden $\frac{.}{\partial}$ and his home. To Mrs. Mutch, who was his perfect helpmate and staunch supporter in $\frac{0}{0}$ all his undertakings, we offer our deep sympathy in her loss.

\section{CorRIgEnda}

IN the article by J. M. Neely on "A Speed-of-Perception Measurement Apparatus", which appeared in the July issue:

Fig. 10, p. 442, the scale marked "Accommodation in Dioptres" should read "Esophoria $\stackrel{\mathbb{D}}{\rightarrow}$ and Exophoria";

1. 9, p. 443, "pupil diameters" should read "prism dioptres". 